\title{
Focal Hepatic Steatosis in A Juvenile Green Sea Turtle - Case Report
}

\author{
Marília De Albuquerque Bonelli, Lorena Adão Vescovi Séllos Costa and Fabiano Séllos Costa* \\ ${ }^{1}$ Department of Veterinary Medicine, Universidade Federal Rural de Pernambuco, Recife, Brazil \\ ${ }^{2}$ Departamento de Medicina Veterinária, Universidade Federal Rural de Pernambuco, Rua Dom Manuel de Medeiros, S/N, Recife-PE, 50870-440
}

${ }^{3}$ Departamento de Medicina Veterinária, Universidade Federal Rural de Pernambuco, Rua Dom Manuel de Medeiros, S/N, Recife-PE, 50870-440

Submission: May 09, 2020; Published: June 11, 2020

*Corresponding author: Fabiano Séllos Costa, Department of Veterinary Medicine, Universidade Federal Rural de Pernambuco, Recife, Brazil

\section{Abstract}

Quantitative computed tomography (QCT) is a highly sensitive, applicable technique. It shows great precision in the diagnosis of alterations in the radiodensity of hepatic parenchyma. Our objective is to report a presumptive diagnosis of hepatic steatosis in a juvenile Green Sea Turtle, Chelonia mydas, using QCT. Helicoidal computed tomography scans were conducted, and regions of interest selected in the liver after multiplanar reconstruction images were obtained. The values obtained for liver parenchyma radiodensity in Hounsfield units varied between -14 and -17 HU in the studied turtle. Comparing these values with those obtained from healthy turtles in previous reports, a presumptive diagnosis of hepatic steatosis was made. The characterization of changes in X-ray attenuation through CT exams in Green Sea Turtles (Chelonia mydas) may help in diagnosing diffuse liver disease in this species.

Keywords: Liver; Steatosis; Computed tomography; Turtle; Chelonia mydas; Reptile

\section{Introduction}

There are currently eight species of sea turtles in the world, six of which inhabit the Atlantic Ocean. Various factors have been considered to contribute to the decline of sea turtle populations, such as fish nets and construction on beach areas that are used as nesting sites. Compared with other marine and terrestrial animals, there is very little information on sea turtles available (including natural history, reproduction, and disease processes) which makes diagnosis and treatment mostly a challenge [1]. Hepatic diseases in chelonians can be caused by infectious agents, inflammatory disease, hepatotoxins, nutritional disease, neoplasia and lipidosis. One of the most common types of liver alterations found in chelonians is hepatic lipidosis. Although it may be a physiological phenomenon, it may also occur pathologically in association with a variety of chronic disease conditions. In various cases, it is a clinical sign, instead of the primary disease. Among predisposing causes of inappropriate hepatic lipid deposition, there are: chronic hypoestrogenism, abnormal thyroid activity, diabetes mellitus, unsuitable diet (excessive energy sources, chronic nutrient deficiency), influence of bacterial and mycotic toxins disrupting lipid metabolisms, starvation, alterations in hibernation (unsuitably long periods, unsuitable temperature), anorexia as a result of primary disease process such as viral diseases, secondary nutritional hyperparathyroidism, inadequate photoperiod or other exogenous factor stimulating inappropriate pre-hibernation metabolism and lipid storage [2].

The liver can be found in the center of the chelonian coelomic cavity and occupies the width behind the heart. It is incompletely divided into lobes (with two dominant ventral lobes), with a small gall bladder at the caudal border on the right side. There is no diaphragm, so the relationship between the liver and other viscera is different when compared to higher vertebrates. Normal liver texture and color are similar to that of other vertebrates [3].

Computed tomography (CT) exams have a broad variety of indications in animals, becoming an important tool for the establishment of several diagnoses [4-9]. In chelonians, computed tomography is considered to provide the best visualization of reticular lung patterns and lung disorders, kidneys, follicles and eggs, urinary bladder and partly the heart, as well as allowing threedimensional reconstructions for surgical planning or teaching. CT also provides sufficient information about the liver, gall bladder, and allows the detection of liver enlargement. Densitometry of the liver would aid in diagnosing fatty-liver disease or dystrophic calcifications [10].

Evaluation of the radiodensity of abdominal organs is widely performed in human medicine [11,12] and can be employed 
with high precision and reproducibility in animals, helping in the diagnosis of alterations in several organs [13-15,5]. The degree of attenuation in HU obtained with CT is considered important in humans for the diagnosis and monitoring of patients with illnesses which alter the hepatic parenchyma, such as steatosis and glycogenosis [11]. Some studies have been conducted using quantitative computed tomography (QCT) for evaluation of hepatic diseases in domestic animals, but there is no mention of its use in reptiles. Our goal is to describe the hepatic radiodensity findings indicative of steatosis with the use of quantitative computed tomography in a juvenile Green Sea Turtle, Chelonia mydas.

A juvenile Green Sea Turtle (Chelonia mydas - Linnaeus, 1758) was captured with the intent of relocation at the final effluent of the ArcelorMittal company (Companhia Siderúrgica de Tubarão), Espírito Santo, Brazil. The turtle was captured with the use of nets, and subsequently transported to a facility where clinical examination and tomographic scans were performed. We were unable to determine gender as the turtle had not yet reached sexual maturity. The turtle was considered to be smaller and less active than other turtles of similar age found at the same location. Carapace length was measured at $35.3 \mathrm{~cm}$, and carapace width at
$32.8 \mathrm{~cm}$. The turtle weighed $4.9 \mathrm{~kg}$. The turtle was anesthetized with propofol ( $5 \mathrm{mg} / \mathrm{kg} \mathrm{IV})$.

The turtle was then positioned in ventral recumbency, and the CT scans were performed with a GE Hi-Speed FXI CT scanner (General Electric) and a protocol using $140 \mathrm{kVp}$ and auto $\mathrm{mA}$ at one rotation per second. Images were obtained in $2 \mathrm{~mm}$ thick transverse slices using a soft tissue reconstruction filter. Prior to the exams, the equipment was calibrated for better standardization of the results. After tomography and digitalization of the images, another set of images was obtained through multiplanar reconstruction to allow better visualization of the liver and identification of right and left hepatic lobes. After a subjective evaluation of the hepatic parenchyma, a quantitative analysis of the degree of x-ray attenuation was performed. A careful analysis was needed for the exclusion of vascular structures from the selected regions of interest. Attenuation in the liver was measured in $\mathrm{HU}$ by calculating the mean between multiple regions of interest (ROI) obtained from both axial and multiplanar reconstruction images. Each ROI had an area of $25 \pm 0.1 \mathrm{~mm}^{2}$ (Figure 1). After a quick recovery from anesthesia, the animal was released at Camburi beach, Vitória, Espírito Santo, Brazil.

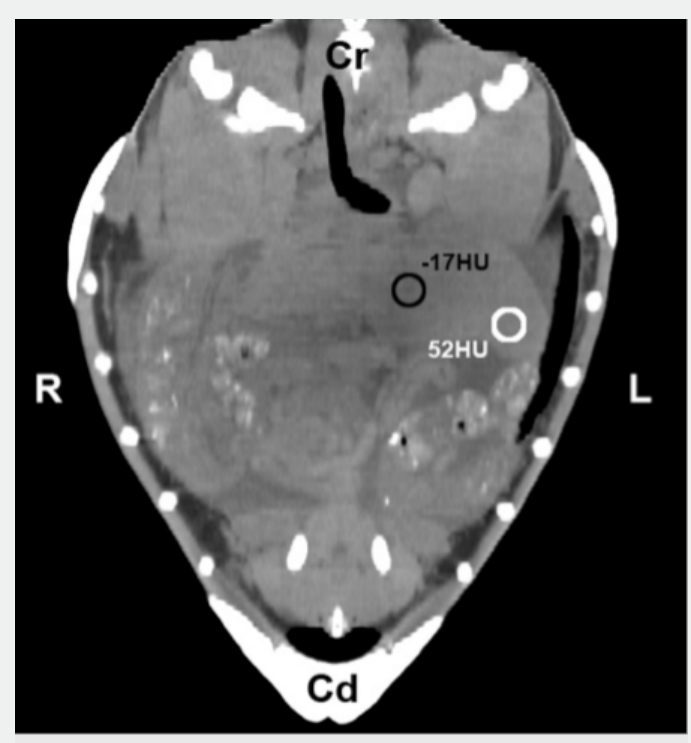

Figure 1: Tomographic imaging of the liver of a Green Sea Turtle, Chelonia mydas, with focal hepatic steatosis after multiplanar reconstruction, showing selected regions of interest (ROI) in the left hepatic lobe, where the black circle represents the area with hypoattenuation, and the white circle, the area considered normal (Dorsal plane - soft-tissue window). (Cr) Cranial; (Cd) Caudal; (L) Left; (R) Right.

The values obtained for liver parenchyma radiodensity in Hounsfield units varied between -14 and -17 HU in the studied turtle. Nakamura et al (2005), when evaluating the clinical application of QCT for the diagnosis of hepatic lipidosis in cats, found a mean of $57.4 \mathrm{HU} \pm 5.6 \mathrm{SD}$ in healthy specimens. Three studies in dogs cite normal values, which always vary between 50 and $70 \mathrm{HU}$ (Cáceres et al. 2006; Costa et al, 2010a; Ohlerth and Scharf, 2007). Forattini et al. [16] obtained a mean radiodensity value of $59.4 \mathrm{HU} \pm 3.9 \mathrm{SD}$ in four healthy juvenile Green Sea Turtles, Chelonia mydas.

Wilkinson et al. [17] consider that a decrease from $50-70$ $\mathrm{HU}$ to $-10--40 \mathrm{HU}$ in liver radiodensity can help in the diagnosis of fatty-liver disease. However, the author does not take into consideration species or age when citing normal values $(50-70$ $\mathrm{HU})$. 
Studies containing tomographic anatomy of the coelomic organs of sea turtles are scarce. Valente et al. [18] performed tomographic studies of juvenile loggerhead sea turtles (Caretta caretta) with the objective of facilitating the identification of clinically revelant organs through auxiliary imaging diagnostics. The authors were able to identify and describe the topographic anatomy of the right and left liver lobes and biliary vesicle after multiplanar reconstruction. In our study, similar images were obtained, which allowed us to perform the measurements related to radiodensity of the hepatic parenchyma.

Computed tomography has a greater sensitivity for small areas of X-ray attenuation, and is thus able to provide high precision information when compared with other methods of diagnostic imaging. In veterinary medicine, CT improves the diagnostic process, providing valuable and auxiliary information to those obtained through other diagnostic methods (Ohlerth and Scharf, 2007; Tidwell, 2007). Particularly in wild animals, auxiliary diagnostic imaging methods, such as CT, have a high relevance due to the difficulty in obtaining data related to history, or even performing a detailed clinical examination of the patient.

For the turtle in question, the images were obtained without intravenous injection of iodine-based contrast media. According to Seeram (2008), though contrast helps in identifying vascular structures, its presence may interfere in liver radiodensity, producing an inaccurate result. The methodology used for evaluating hepatic parenchyma radiodensity was effective and easily permitted obtaining the measurements.

The radiodensity values obtained during CT exam correspond to the mean attenuation of pixels present in the selected ROI, in HU [18]. In this report, the areas selected as regions of interest for evaluation of hepatic parenchyma had a mean area of $25 \mathrm{~mm}^{2} \pm$ $0.1 \mathrm{SD}$. This procedure has also been described by other authors, where it is mentioned that the standardization of the ROI size is important for allowing a greater precision in results (Costa et al. 2010; Kodama et al., 2007). Different locations of the hepatic parenchyma were evaluated, and some areas of hypoattenuation were seen on the left hepatic lobe. Regions of interest were then selected in the affected area, where a radiodensity oscillating between -14 and -17 HU was observed.

Various diffuse alterations that can affect the liver and possibly alter its density are difficult to differentiate clinically or through other diagnostic imaging methods. As an example, there are hepatopathies which cause accumulation of hepatic glycogen, leading to increased radiodensity and hepatic steatosis, resulting in decreased radiodensity through lipid accumulation in hepatocytes (Nakamura et al., 2005; Ohlerth and Scharf, 2007). In humans, QCT is routinelly used to differentiate hepatic glycogenosis and steatosis, foregoing the need for a liver biopsy. Glycogenosis promotes the increase of hepatic radiodensity, as has been verified in human patients [19] and rats (Leander, 2000). Accumulation of hepatic glycogen is the main cause for increased density in human livers. In vitro studies demonstrate that, for each $1 \%$ increase in concentration of hepatic glycogen, an increase in the X-ray attenuation coefficient between 2.5 and $3.0 \mathrm{HU}$ occurs on CT exam (Rockall et al., 2003). According to previous reports, there is a decrease in hepatic radiodensity of approximately 1.0 to $1.5 \mathrm{HU}$ for each $1 \%$ increase in lipid concentration in the liver [12].

A presumptive diagnosis was made of focal hepatic steatosis, seeing as there were areas of the liver with what [20] considered to be normal radiodensity values for the species, and areas that had a lower radiodensity. The use of QCT for this diagnosis would allow veterinarians to avoid more invasive procedures, such as liver biopsies, which can be difficult especially in free-ranging animals [21-23].

The characterization of changes in X-ray attenuation through CT exams in Green Sea Turtles may help in diagnosing diffuse liver disease in this species [24]. Furthermore, after standardization of normality values for different species, quantitative computed tomography may help in the diagnosis of liver diseases in captive and free-ranging animals.

\section{References}

1. Tristan, $\mathrm{T}$ (2008) Introduction to Hematology and Biochemistry in Sea Turtles. Proceeding of the ACVP/ASVCP, USA.

2. Mc Arthur S (2004) Problem-solving approach to common diseases of terrestrial and semi-aquatic chelonians. In (eds.), Mc Arthur, R Wilkinson, J Meyer, Medicine and Surgery of Tortoises and Turtles, Blackwell, UK, pp. 309-377.

3. Mc Arthur S, J Meyer, C Innis (2004) Anatomy and Physiology. In: McArthur S, Wilkinson R, and Meyer J, Medicine and Surgery of Tortoises and Turtles, pp. 35-71. Blackwell, UK.

4. Nakamura M, HM Chen, Y Momoi, T Iwasaki (2005) Clinical application of computed tomography for the diagnosis of feline hepatic lipidosis. Journal of Veterinary Medical Science 67(11): 1163-1165.

5. Ohlerth S, G Sharf (2007) Computed tomography in small animals: Basic principles and state of the art applications. The Veterinary Journal 173(2): 254-271.

6. Rockall A G, SA Sohaib, D Evans, G Kaltsas, AM Isidori, (2003) Hepatic steatosis in Cushing's syndrome: a radiological assessment using computed tomography. European Journal of Endocrinology 149(2): 543548.

7. Seeram, E (2008) Computed Tomography: Physical Principles, Clinical Applications, and Quality Control. Elsevier Saunders, USA.

8. Smallwood JE, TF George II (1993) Anatomic atlas for computed tomography in the mesaticephalic dog: thorax and cranial abdomen. Veterinary Radiology \& Ultrasound 34: 65-84.

9. Teixeira M, F Gil JM, Vazquez L Cardoso, Arencibia A, Ramirez-Zarzosa G (2007) Helical computed tomographic anatomy of the canine abdomen. Vet J174(1): 133-138.

10. Wilkinson R, Hernandez-Divers S, Lafortune M, Calvert I, Gumpenberger M, et al. (2004) Diagnostic Imaging Techniques. In S. McArthur, R. Wilkinson, and J. Meyer, Medicine and Surgery of Tortoises and Turtles, Blackwell, UK pp.187-238.

11. Kodama Y, CS Ng, Wu TT, Ayers GD, Curley SA, Abdalla EK (2007) Comparison of CT methods for determining the fat content of the liver. AJR Am J Roentgenol 188(5): 1307-1321. 
12. Tatsuhiro Tsujimoto, Masato Takano, Mariko Nishiofuku, Hitoshi Yoshiji, Yoshinobu Matsumura (2006) Rapid onset of glycogen storage hepatomegaly in a type-2 diabetic patient after a massive dose of long-acting insulin and large doses of glucose. Intern Med 45(7): 469-473.

13. Costa L AVS, LFP Maestri JA, Maia, VC Silva, AB Lanis, et al. (2010) Hepatic radiodensity in healthy dogs by helical computed tomography. Ciência Rural 40(4): 888-893.

14. Leander P, Mansson S, Pettersson G (2000) Glycogen content in rat liver: Importance for CT and MR imaging. Acta Radiol 41(1): 92-96.

15. Winter MD, LM Kinney, LJ Kleine (2005) Three-dimensional helical computed tomography angiography of the liver in five dogs. Veterinary Radiology \& Ultrasound 46(6): 494-499.

16. Forattini JG (2011) Concentrações de Testosterona Plasmática em um População Juvenil de Chelonia mydas, no efluente industrial de uma companhia siderúrgica - Vitória, Espírito Santo. Masters. Dissertation, Vila Velha University Center, Brazil

17. Valente ALS, Cuenca R, Zamora M, Parga ML, Lavin S (2007) Computed tomography of vertebral column and coelomic structures in the normal loggerhead sea turtle (Caretta caretta). Vet J 174(2): 362-370.

18. Adams JE (2009) Quantitative computed tomography. Eur J Radiol 71 415-424.
19. Doppman JL, Cornblath M, Dwyer AJ, Adams AJ, Girton ME, et al. (1982) Computed tomography of the liver and kidneys in glycogen storage disease. Journal of Computed Assisted Tomography 6(1): 67-71.

20. Forattini JG, Rossi Júnior JL, FLG Leite DC, Oliveira, LAVS Costa, et al (2011) Tomografia computadorizada quantitativa do fígado de tartarugas verdes juvenis "Chelonia mydas”. Medicina Veterinária 5(Supl.1): 273-275.

21. Ana V Cáceres, Allison L Zwingenberger, Erin Hardam, José M Lucena, Tobias Schwarz (2006) Helical computed tomographic angiography of the normal canine pancreas. Vet Radiol Ultrasound 47(3): 270-278.

22. LAVS Costa, Lopes BF, Lanis AB, De Oliveira DC, Giannotti JG, et al. (2010) Bone demineralization in the lumbar spine in dogs submitted to prednisone therapy. J Vet Pharmacol Ther 33(6): 583-586.

23. Linnaeus C (1758) Tomus I Systema naturae per regna tria naturae secundum classes, ordines, genera, species, cum characteribus, differentiis, synonymis, locis. Holmiae. (Laurentii Salvii): [1-4], 1-824.

24. Tidwell AS (2007) Principle of computed tomography and magnetic resonance imaging. In D. E. Thrall, Veterinary Diagnostic Radiology, pp. 50-77. Saunders Elsevier, USA.

\section{Your next submission with Juniper Publishers} will reach you the below assets

- Quality Editorial service

- Swift Peer Review

- Reprints availability

- E-prints Service

- Manuscript Podcast for convenient understanding

- Global attainment for your research

- Manuscript accessibility in different formats ( Pdf, E-pub, Full Text, Audio)

- Unceasing customer service

Track the below URL for one-step submission https://juniperpublishers.com/online-submission.php 